\title{
'Lack of behaviour studies is hampering AIDS prevention'
}

Washington. The United States should fund a national survey to fill gaps in current knowledge of sexual practices and drug use and their links to HIV infection, according to a panel of experts convened by the Institute of Medicine (IOM). In a report published last week, the panel says that the lack of such knowledge is hampering efforts to prevent the spread of AIDS.

In the past, requests for federal funding for any survey that includes questions about sexual practices have been opposed by powerful conservative voices in Congress, backed by fierce grass-roots opposition through the television evangelist network.

The IOM panel's clear call for a federally funded survey of sex and drug use means that members of Congress will once again have to face the issue, and decide whether to give in to pressure from the religious right.

The IOM report was commissioned by Congress in 1992 in an attempt to assess the balance of biomedical and behavioural research conducted in the National Institute of Alcohol and Alcoholism, the National Institute of Drug Abuse and the National Institutc of Mental Health.

It was prompted by AIDS activists who felt that not enough was being spent on research in the behavioural and social sciences to help public health officials devise more effective prevention techniques.

According to one congressional aide, now that the IOM has endorsed a full survey, the need is for scientists at the National Institutes of Health to add their backing. The Bush administration had refused to provide support. "But the political climate has changed, and there is more chance that a sex survey would get federal funding, although it is not certain."

Mindy Thompson-Fullilove, associate professor of clinical psychology and public health at Columbia University in New York, and a member of the IOM panel, points out that the United States carries out annual surveys of drug use and violence, which are illegal, but not about legal sexual practices. "Without the information from such a survey, we all feel profoundly crippled in attempts to devise effective prevention messages," she says.

Fullilove claims that the anti-AIDS messages put out by the Public Health Service have not been sufficiently frequent, frank or well-targeted. "We need to know a lot more, say, about how people view barrier protection," she says. "A lot of people say they don't like condoms, but some research suggests that they might have used them once and had a bad experience. If that is the case then the advertisement would be different than for people who have never used them."
Sex surveys have been conducted in the past in the United States, but with private funds. One, at the University of Chicago, started out by requesting federal funds, but the political opposition was so strong that a private foundation took over.

Another survey, conducted by the Center for AIDS Prevention Studies in San Francisco, canvassed 14,000 people by telephone. But critics of such an approach say that many of those who should be reached by a survey may not have a telephone. "We need a national survey for the rational development of public policy," says Fullilove.

The report also calls for more research on the social behaviour of individuals. "We know very little about what pressures are brought to bear on a person by peers or families or communities," says Judy Auerbach, the panel's study director. Fullilove, for example, points out that it is often unacceptable for Hispanic women to talk about sex, and that this may affect their ability to negotiate the use of a condom.

Another example of potentially useful social science research, says Fullilove, is detailed mapping by medical geographers showing the location of infected individuals on a street-by-street basis. The first use of medical mapping was in London in 1854, when an outbreak of cholera was traced to a single water pump. "We already know that HIV infection correlates strongly with urban decay, [but] we need to know what is analogous to the water pump," says Fullilove.

Finally the panel says that a better understanding is needed of how the AIDS epidemic interacts with, for example, tuberculosis and violence. At times the immune system 'locks up' HIV, but at others - such as when the patient has tuberculosis - it does not. "Does the TB epidemic affect the HIV epidemic?" asks Fullilove. "We don't know, and we need to know." Helen Gavaghan

\section{Minister is rebuffed over bid to require publishing in French}

Paris. French research organizations breathed a sigh of relief last week when the country's constitutional council rejected a provision of a new law that would have required virtually all publicly funded research to be published in French. The law would have allowed the research ministry to make individual exemptions. But the constitutional council rejected the whole provision as contrary to "freedom of communication and expression in teaching and research".

The provision was contained in a wideranging law on the use of the French language drawn up by Jacques Toubon, the minister of culture, and recently adopted by both the National Assembly and Senate.

The council's decision was part of a longer judgement rejecting various elements of the new law. A long campaign by research organizations - in particular, the French Academy of Sciences - to have other restrictive provisions watered down also seems to have been successful.

For example, although the council has approved an article giving all participants at scientific meetings in France the "right to express themselves in French", the article no longer insists on simultaneous translation.

The Centre National de la Recherche Scientifique (CNRS), the country's largest research body, bluntly told the government that this would cost it FF10 million(US\$1.84 million) a year.

The council has approved the requirement that conference proceedings from such events should carry at least an abstract in French. Such abstracts will also be required in foreign journals or magazines that receive subsidies from French public bodies.

But research organizations are confident that the decree, yet to be published, in which the government specifies how these and other provisions are to be enforced, will take account of their concerns. Declan Butler

\section{UK insurers drop enquiry on HIV testing}

London. The Association of British Life Insurers (ABI) last week advised its member insurance companies to stop asking applicants whether they have had HIV/ AIDS tests or counselling. But the association is still recommending that applicants be asked if they have ever received either a positive test result, or treatment for HIV/AIDS or hepatitis.

The move reflects the fact that the disease has had a smaller impact on insurance payouts than originally predicted. Since 1987, when the question was introduced on application forms, British insurers have paid out more than $\mathbf{1 5 0}$ million for deaths in which HIV or AIDS was implicated, considerably less than had been anticipated.

Insurance companies had previously wanted to be able either to refuse a policy or to charge higher premiums to an applicant who had taken a test, even if the test results were negative. This was based on the assumption that only people who consider themselves at high risk were likely to have taken a test.

But the $\mathrm{ABI}$, in recommending a change which has been widely welcomed by AIDS charities, admits that testing for HIV/ AIDS is now more widespread than anticipated, and is used by individuals for many reasons. 